\title{
ANALISIS BIAYA, PENERIMAAN DAN R/C AGROINDUSTRI TEPUNG TAPIOKA \\ (Studi Kasus Pada Agroindustri Tepung Tapioka di Desa Bojongasih Kecamatan Bojongasih Kabupaten Tasikmalaya)
}

\author{
AGUS KURNIAWAN ${ }^{1}$, DINI ROCHDIANI ${ }^{2}$, DANI LUKMAN HAKIM ${ }^{1}$ \\ ${ }^{1}$ Fakultas Pertanian Universitas Galuh \\ ${ }^{2}$ Fakultas Pertanian Universitas Padjadjaran \\ E-mail : aguskurniawan1207@gmail.com
}

\begin{abstract}
ABSTRAK
Penelitian ini bertujuan untuk mengetahui: 1) Besarnya biaya dan penerimaan pada agroindustri tepung tapioka di Desa Bojongasih Kecamatan Bojongasih Kabupaten Tasikmalaya, 2) Besarnya pendapatan dan R/C pada agroindustri tepung tapioka di Desa Bojongasih Kecamatan Bojongasih Kabupaten Tasikmalaya. Penelitian ini dilaksanakan di Desa Bojongasih Kecamatan Bojongasih Kabupaten Tasikmalaya. Diketahui bahwa lokasi agroindustri tepung tapioka di Desa Bojongasih dapat dikatakan strategis karena memiliki sumber air dan akses sumber matahari yang baik untuk melaksanakan produksi. Sumber air dan matahari sangat penting bagi industri pengolahan tepung tapioka sehingga sangat mendukung keberhasilan usaha industri tepung tapioka. Serta memiliki tempat pembuangan limbah yang jauh dari pemukiman penduduk, sehingga tidak memberikan dampak buruk bagi masyarakat sekitar. Metode yang digunakan dalam penelitian ini adalah studi kasus dengan mengambil kasus pada seorang pengusaha agroindustri tepung tapioka. Responden yang diambil dalam penelitian ini diambil secara sengaja (purposive sampling), yaitu pada agroindustri tepung tapioka di Desa Bojongasih Kecamatan Bojongasih Kabupaten Tasikmalaya. Hasil penelitian menunjukkan bahwa : 1) Besarnya biaya agroindustri tepung tapioka per satu kali proses produksi adalah sebesar $\mathrm{Rp} 19.936494$, penerimaan sebesar $\mathrm{Rp} 22.560 .000$, 2) pendapatan sebesar $\mathrm{Rp}$ 2.623.506 dan R/C agroindustri tepung tapioka adalah 1,13. Dengan demikian usaha agroindustri tepung tapioka menguntungkan.
\end{abstract}

Kata Kunci : Penerimaan, R/C, Agroindustri, Tapioka

\section{ABSTRACT}

This objectives of the study were : 1) This study aims to determine: 1) The amount of costs and revenues in tapioca flour agroindustry in Bojongasih Village, Bojongasih District, Tasikmalaya Regency, 2) The amount of income and R/C in tapioca flour agroindustry in Bojongasih Village, Bojongasih District, Tasikmalaya District. This research was conducted in Bojongasih Village, Bojongasih District, Tasikmalaya Regency. It is known that the location of tapioca flour agroindustry in Bojongasih Village can be said to be strategic because it has a good water source and access to solar sources to carry out production. Water and solar sources are very important for the tapioca flour processing industry so it is very supportive of the success of the tapioca flour industry. As well as having a landfill that is far from residential areas, so it does not have a bad impact on the surrounding community. The method used in this research is a case study by taking a case in a tapioca flour agroindustry entrepreneur. Respondents taken in this study were taken deliberately (purposive sampling), namely in tapioca flour agroindustry in Bojongasih Village, Bojongasih District, Tasikmalaya Regency. The results showed that: 1) The amount of tapioca flour agro-industry costs per one-time production process was $R p$ 19,936,494, revenue was $R p$ 22,560,000, 2) revenue was $R p 2,623,506$ and the $R / C$ of tapioca flour agro-industry was 1.13. Thus the tapioca flour agro-industry is profitable.

Keywords: Revenue, R/C, Agroindustry, Tapioca 


\section{PENDAHULUAN}

Sektor pertanian merupakan salah satu sumber utama kehidupan dan pendapatan sebagian besar masyarakat tani, menghasilkan pangan bagi masyarakat, penghasil bahan baku, dan bahan bantu bagi industri pengolahan, penyedia lapangan pekerjaan dan usaha (Sutardi, 2017).

Strategi pembangunan bagi negara seperti Indonesia yang stimultan mempunyai potensi besar di sektor pertanian serta ingin menuju sektor industri adalah strategi yang menjaga keseimbangan antara sektor indusrti dengan sektor pertanian. Oleh karena itu, yang paling sesuai dengan pengolahan produk pertanian melalui pengembangan agroindustri (Baharsyah, 2009).

Akan tetapi dalam pengembangan agroindustri ada beberapa kendala yang harus diperhitungkan, yang disebabkan oleh karakteristik agroindustri yang memilik hubungan ke depan dan ke belakang dibandingkan sektor-sektor yang lain.

Menurut Ushada (2019), kendalakendala tersebut terdiri dari :

1) Jaminan kualitas dan kesinambungan produk hasil pertanian, adanya keterbatasan bahan baku yang dihasilkan para petani yang belum sesuai dengan kebutuhan agroindustri yang memiliki kebutuhan yang runtut dan kualitas yang tinggi. Penyebabnya disebabkan oleh kurangnya pendanaan dan teknologi yang sesuai.

2) Kapasitas sumberdaya manusia yang relatif rendah, kurangnya kemampuan dalam menggunakan teknologi agroindustri yang bisa berdampak pada efisiensi industri rendah dibandingkan dengan negara pesaing.

3) Teknologi sederhana yang digunakan oleh kebanyakan agroindustri, dan kurangnya pengembangan kemitraan antara pelaku industri, pemerintah dan akademisi.

Dalammempertahankan keberhasilan sektor pertanian diperlukan adanya suatu perencanaan pembangunan sektor pertanian salah satunya dengan melakukan investasi agar dapat memicu kenaikan output dan input yang akan berpengaruh terhadap kenaikan pendapatan, kesempatan kerja, serta mendorong tumbuhnya perekonomian Indonesia (Sjamsir, 2017). Oleh sebab itu, pembangunan sektor industri harus dimulai dari mulai pengolahan produk pertanian menjadi menjadi produk industri melalui pengembangan agroindustri.

Dengan begitu menciptakan komoditas pertanian berdaya saing tinggi 
yang dihasilkan dengan meningkatkan produktivitas dan efisiensi, baik di tingkat praproduksi, proses produksi, dengan menggunakan teknologi tepat guna dan manajemen profesional (Arwati, 2018). Terkait dengan perkembangan agroindustri ke depan telah jelas, yang memiliki visi agroindustri berbasis teknologi dan berwawasan nilai tambah, serta mampu menghasilkan produk berdaya saing tinggi, sehingga agroindustri dapat menjadi tulang punggung perekonomian nasional (Rahman, 2018).

Menurut Susilawati (2008), ubi kayu merupakan sumber bahan makanan ketiga di Indonesia setelah padi dan jagung. Namun dengan berkembangnya teknologi ubi kayu dijadikan sebagai olahan industri makanan seperti sumber utama pembuatan pati. Selama ini produksi ubi kayu yang berlimpah sebagian besar digunakan dalam industri tepung tapioka.

Pada tahun 2016, areal penanaman singkong di Indonesia mencapai luas 1.382.902 ha dengan produksi sebesar 12.902.011 ton. Adapun perinciannya untuk keperluan industri yaitu 341.000 ton, dan yang lainnya untuk keperluan lain. Sehingga kebutuhan ubi kayu dipastikan akan meningkat tajam sehingga diperlukan peningkatan dalam produksinya baik melalui peningkatan produktivitas maupun perluasan areal tanam serta dalam pengolahan agroindustrinya.

Pada saat ini bahan baku ubi kayu memang agak sulit untuk di dapatkan yang disebabkan kurangnya minat para petani dalam berusaha tani ubi kayu. Namun di Kabupaten Tasikmalaya memiliki potensi besar di bidang agroindustri tepung tapioka, salah satunya ada di Desa Bojongasih Kecamatan Bojongasih Kabupaten Tasikmalaya.

Walaupun sebagian pelaku industri tepung tapioka yang berhenti berproduksi karena disebabkan sulitnya mendapatkan bahan baku ubi kayu, namun agroindustri tepung tapioka di Desa Bojongasih tetap berproduksi karena melihat kebutuhan akan tepung tapioka pada saat ini yang semakin meningkat, yang disebabkan oleh banyaknya pelaku industri makanan yang berbahan dasar tepung tapioka.

Bahkan Indonesia sendiri masih sangat ketergantungan cukup besar terhadap komoditas ubi kayu sehingga untuk melakukan produksi tepung tapioka harus mengimpor bahan baku untuk memenuhi produksi tepung tapioka. Karena kebutuhan akan tepung tapioka sangat besar maka diperlukan pembahasan mengenai hubungan antara petani dengan industri melalu program kemitraan. 
Berdasarkan data dari Dinas Perindustrian dan Perdagangan Kabupaten Tasikmalaya (2017) terdapat beberapa agroindustri tepung tapioka di Kabupaten Tasikmalaya, sebagaimana dapat dilihat pada Tabel 1.

Tabel 1. Data Agroindustri Tepung Tapioka di Kabupaten Tasikmalaya Tahun 2017.

\begin{tabular}{|c|c|c|c|c|c|c|}
\hline No. & $\begin{array}{c}\text { Nama } \\
\text { Perusahaan }\end{array}$ & Nama Pengusaha & Kecamatan & Desa & $\begin{array}{l}\text { Nilai Investasi } \\
\quad(\mathbf{R p})\end{array}$ & $\begin{array}{c}\text { Tenaga } \\
\text { Kerja } \\
\text { (Orang) }\end{array}$ \\
\hline 1. & $\begin{array}{c}\text { Karya Subur } \\
\text { Sentosa }\end{array}$ & Lieo Jin & Manonjaya & Cilangkap & 1.000 .000 .000 & 26 \\
\hline 2. & - & Karta & Cineam & Cijulang & 8.500 .000 & 5 \\
\hline 3. & Aneka Jaya & Solehudin & Jatiwaras & Kertahayu & 17.000 .000 & 7 \\
\hline 4. & $\begin{array}{l}\text { Pabrik Aci } \\
\text { Cinunjang }\end{array}$ & $\begin{array}{l}\text { H. Ujo Johar } \\
\text { Aripin }\end{array}$ & $\begin{array}{l}\text { Gunung } \\
\text { Taniung }\end{array}$ & Cinunjang & 22.000 .000 & 15 \\
\hline 5. & - & Harun Spd & Cineam & Cikondang & 10.000 .000 & 5 \\
\hline 6. & Cahaya Murni & H. Oyon & Cineam & Cikondang & 18.500 .000 & 10 \\
\hline 7. & $\begin{array}{l}\text { Pabrik Aci } \\
\text { Madur }\end{array}$ & Tendi Sasmita & Bojongasih & Bojongasih & 2.000 .000 .000 & 28 \\
\hline 8. & $\begin{array}{l}\text { Perusahaan } \\
\text { Aci Singkup }\end{array}$ & Cecep Kustiawan & Jatiwaras & Setiawangi & 20.000 .000 & 8 \\
\hline 9. & - & Ikin Sanjaya & $\begin{array}{c}\text { Karang } \\
\text { Nunggal }\end{array}$ & $\begin{array}{c}\text { Karang } \\
\text { Nunggal }\end{array}$ & 32.500 .000 & 14 \\
\hline 10. & - & Tatang D.H & Cineam & Nagaratengah & & \\
\hline
\end{tabular}

Sumber : Laporan Tahunan., Dinas Perindustrian dan Perdagangan Kabupaten Tasikmalaya, 2017

Berdasarkan Tabel 1 di atas, menunjukkan bahwa nilai investasi terbesar agroindustri tepung tapioka yaitu ada di Desa Bojongasih Kecamatan Bojongasih Kabupaten Tasikmalaya, dibandingkan dengan 9 agroindustri tepung tapioka lainnya yang ada di Kabupaten Tasikmalaya. Berdasarkan survey awal, diketahui bahwa lokasi agroindustri tepung tapioka di Desa Bojongasih dapat dikatakan strategis karena memiliki sumber air dan akses sumber matahari yang baik untuk melaksanakan produksi. Sumber air dan matahari sangat penting bagi industri pengolahan tepung tapioka sehingga sangat mendukung keberhasilan usaha industri tepung tapioka.

Serta memiliki tempat pembuangan limbah yang jauh dari pemukiman penduduk, sehingga tidak memberikan dampak buruk bagi masyarakat sekitar. Sebagaimana permasalahan agroindustri pada umumnya, hasil pengamatan di lapangan menunjukkan bahwa agroindustri tepung tapioka di Desa Bojongasih secara umum tidak pernah memperhitungkan besarnya biaya yang dikeluarkan sehingga berdampak pada tidak diketahuinya secara pasti besarnya biaya, penerimaan serta $\mathrm{R} / \mathrm{C}$ yang diperoleh. Sehubungan dengan hal tersebut penulis tertarik untuk melakukan 
penelitian mengenai "Analisis Biaya, Penerimaan dan R/C pada Agroindustri Tepung Tapioka" di Desa Bojongasih Kecamatan Bojongasih Kabupaten Tasikmalaya.

\section{METODE PENELITIAN}

Jenis Penelitian yang digunakan dalam penelitian ini adalah studi kasus dengan mengambil kasus pada Perusahaan Agroindustri Tepung di Desa Bojongasih Kecamatan Bojongasih Kabupaten Tasikmalaya. Studi kasus adalah suatu metode untuk memahami individu yang dilakukan secara integrative dan komprehensif agar diperoleh pemahaman yang mendalam tentang individu tersebut beserta masalah yang dihadapinya dengan tujuan masalahnya dapat terselesaikan dan memperoleh perkembangan diri yang baik (Rahardjo dan Gudnanto, 2011).

\section{TEKNIK PENGUMPULAN DATA}

Data yang digunakan dalam penelitian ini meliputi data primer dan data sekunder. Data primer diperoleh dari wawancara berdasarkan kuesioner yang telah disiapkan sebelumnya terhadap responden atau pengelelola agroindustri tepung tapioka. Data sekunder diperoleh dari instansi atau lembaga yang terkait dan dari berbagai literatur yang berhubungan dengan penelitian ini.

\section{TEKNIK PENARIKAN SAMPEL}

Teknik penarikan sampel dalam penelitian ini menggunakan teknik purposive sampling. Menurut Sugiyono (2018) purposive sampling adalah teknik penentuan sampel dengan pertimbangan tertentu.

Agroindustri tepung tapioka dipilih secara sengaja sebagai sampel dengan pertimbangan karena agroindustri tepung tapioka yang ada di Desa Bojongasih Kecamatan Bojongasih merupakan agroindustri tepung tapioka yang memiliki nilai investasi terbesar di Kabupaten Tasikmalaya.

\section{RANCANGAN ANALISIS DATA}

Data yang diperoleh dari lapangan kemudian dianalisis sesuai dengan tujuan penelitian, yaitu: meliputi analisis pendapatan, penerimaan, dan biaya agroindustri pengolahan tepung tapioka.

\section{a. Biaya Produksi}

Menurut Nafarin (2009) biaya produksi semua biaya yang berkaitan dengan produk (barang) yang diperoleh, dimana di dalamnya terdapat unsur biaya produk berupa biaya bahan baku, biaya 
tenaga kerja langsung dan biaya overhead pabrik. berikut :

Biaya Produksi dirumuskan sebagai $\mathrm{TC}=\mathrm{TFC}+\mathrm{TVC}$

Keterangan :

$\mathrm{TC}=$ Total Cost (Biaya total)

TFC = Total Fixed (Total Biaya)

$\mathrm{TVC}=$ Total Variable Cost (Total biaya variabel)

\section{b. Penerimaan}

Menurut Soekartawi (2010), bahwa penerimaan total (Total Revenue) dari suatu usaha dapat diperoleh dari hasil perkalian antara jumlah produk yang dihasilkan (terjual) dengan harga dari produk tersebut. Secara matematis dituliskan dengan rumus :

$\mathrm{TR}=\mathrm{Y} \times \mathrm{Py}$

Keterangan :

$\mathrm{TR}=$ Total Revenue (Total penerimaan)

$\mathrm{Y}=$ Produksi

Py $=$ Harga produk

\section{c. Pendapatan}

Menurut Soekartawi

(2010)

pendapatan merupakan pengurangan antara penerimaan dengan biaya total. Tingkat pendapatan dari suatu kegiatan agroindustri dapat digunakan rumus :

$$
\pi=\mathrm{TR}-\mathrm{TC}
$$

Keterangan :

$$
\begin{aligned}
& \pi=\text { Keuntungan } \\
& \text { TR = Total penerimaan } \\
& \text { TC }=\text { Biaya Total }
\end{aligned}
$$

\section{d. $\mathbf{R} / \mathrm{C}$}

Dihitung menggunakan rumus menurut Rodjak (2006) sebagai berikut :

$\mathrm{R} / \mathrm{C}=\frac{T R}{T C}$

Dimana :

$\mathrm{R} / \mathrm{C}=$ Revenue Cost Ratio

$\mathrm{TR}=$ Penerimaan Total (Total

Rrevenue)

$\mathrm{TC}=$ Biaya Total (Total Cost)

Dengan kriteria sebagai berikut :

- $\mathrm{R} / \mathrm{C}>1$, maka setiap satu rupiah biaya yang dikeluarkan menghasilkan penerimaan lebih dari satu rupiah, berarti agroindustri menguntungkan.

- $\mathrm{R} / \mathrm{C}=1$, maka setiap satu rupiah biaya yang dikeluarkan menghasilkan penerimaan sama dengan satu rupiah, berarti agroindustri berada dititik impas (balik modal) karena tidak untung, tidak rugi.

- $\mathrm{R} / \mathrm{C}<1$, maka setiap satu rupiah biaya yang dikeluarkan menghasilkan penerimaan lebih kecil dari 1, berarti agroindustri mengalami kerugian.

\section{HASIL DAN PEMBAHASAN}

Analisis usaha agroindustri tepung tapioka terdiri atas analisis biaya, penerimaan, pendapatan dan $\mathrm{R} / \mathrm{C}$ yang dihitung dalam satu kali proses produksi. Dimana proses produksi rata-rata 
dilakukan 180 kali dalam setahun. Biaya tetap yang dihitung dalam penelitian ini meliputi PBB, perijinan, penyusutan alat yang digunakan pada proses produksi, serta bunga bank biaya tetap (Tabel 2).

Tabel 2. Biaya Tetap, Biaya Variabel dan Biaya Total pada Agroindustri Tepung Tapioka per Satu Kali Proses Produksi Tahun 2019

\begin{tabular}{|c|c|c|c|}
\hline No & Jenis biaya & Jumlah biaya (Rp) & Persentase $(\%)$ \\
\hline \multirow[t]{5}{*}{1} & Biaya Tetap : & & \\
\hline & - Pajak Bumi dan Bangunan & 4.583 & 2,15 \\
\hline & - Penyusutan Alat & 197.554 & 93,09 \\
\hline & - Bunga bank Biaya Tetap & 10.107 & 4,76 \\
\hline & Biaya Tetap Total & 212.244 & 100,00 \\
\hline \multirow[t]{10}{*}{2} & Biaya Variabel : & & \\
\hline & - Ubi Kayu & 16.000 .000 & 81,1 \\
\hline & - Solar & 515.000 & 2,5 \\
\hline & - Karung & 186.000 & 0,93 \\
\hline & - Benang & 35.000 & 0,17 \\
\hline & - Listrik & 65.000 & 0,33 \\
\hline & - Tenaga Kerja & 1.984 .000 & 10,4 \\
\hline & - Bunga bank Biaya Variabel & 939.250 & 4,76 \\
\hline & Biaya Variabel Total & 19.724 .250 & 100,00 \\
\hline & Biaya Total & 19.936 .494 & \\
\hline
\end{tabular}

Sumber : Data Primer diolah, 2019

Tabel 2. menunjukkan bahwa biaya variabel yang paling dominan dalam proses produksi ubi kayu menjadi tepung tapioka adalah bahan (81,1 persen) dari total biaya variabel yang dikeluarkan. Dominannya biaya bahan baku dapat dipahami mengingat ubi kayu merupakan hal utama yang diperlukan dalam produksi tepung tapioka. Penerimaan agroindustri tepung tapioka diperoleh dari hasil perkalian antara hasil produksi dengan harga jual tepung tapioka dalam satu kali proses produksi (Tabel 3). 
Tabel 3. Produksi, Harga Produk dan Penerimaan Agroindustri Tepung Tapioka per Satu Kali Proses Produksi Tahun 2019

\begin{tabular}{crccr}
\hline No & Uraian & Produksi & Harga (Rp) & \multicolumn{2}{c}{ Penerimaan (Rp) } \\
\hline 1. & Tepung Tapioka & 2.480 & 9.000 & 22.320 .000 \\
2. & Onggok & 600 & 4.00 & 240.000 \\
\hline \multicolumn{3}{c}{ Jumlah } & & 22.560 .000
\end{tabular}

Sumber : Data primer diolah, 2019

Tabel 3. Menunjukkan penerimaan agroindustri tepung tapioka pada perusaahan agroindustri tepung tapioka di Desa Bojongasih dihitung dengan menggunakan perkalian hasil produksi tepung tapioka dalam satu kali proses produksi dengan harga jual pada saat penelitian. Bahan baku yang digunakan dalam satu kali proses produksi adalah $10.000 \mathrm{~kg} / \mathrm{ton}$, yang menghasilkan tepung tapioka kering dan onggok.

Jumlah produk tepung tapioka yang dihasilkan dalam satu kali proses produksi yaitu $2.480 \mathrm{~kg}$, dan ampas ubi kayu yang berupa onggok $600 \mathrm{~kg}$. Jadi hasil bersih tepung tapioka yang dihasilkan yaitu 2.480 kg. Dengan harga jual tepung tapioka adalah $\mathrm{Rp} 9.000 / \mathrm{kg}$, serta ampas onggok dijual dengan harga $\quad$ Rp 400/kg.

Maka penerimaan tepung tapioka yang diperoleh pengusaha adalah $\quad R p$ 22.320.000, kemudian ditambah dengan penjualan ampas onggok sebanyak $600 \mathrm{Kg}$ dengan harga jual $\mathrm{Rp} 400 / \mathrm{Kg}$, dan menghasilkan penerimaan $\quad \mathrm{Rp}$ 240.000. Jadi total penerimaan yang diperoleh pengusaha dari agroindustri tepung tapioka adalah $\operatorname{Rp} 22.560 .000$.-

Untuk mengetahui besarnya pendapatan atau keuntungan agroindustri tepung tapioka di Desa Bojongaish diperoleh dari hasil pengurangan penerimaan dengan jumlah biaya produksi.

Menurut Rahim dan Hastuti (2007), menyatakan penerimaan merupakan perkalian antara produksi yang dihasilkan dengan harga jual. Untuk memperoleh pendapatan dan keuntungan, produsen selalu membandingkan biaya produksi dengan penerimaan yang diperoleh dari hasil penjualan outputnya.

Layak dan tidaknya usaha agroindustri Tepung Tapioka didekati dengan analisis $\mathrm{R} / \mathrm{C}$, yaitu nisbah antara penerimaan total dengan biaya produksi total. Analisis penerimaan, pendapatan dan R/C agroindustri Tepung Tapioka dapat dilihat pada Tabel 4. 
Tabel 4. Penerimaan, Biaya Total, Pendapatan dan R/C Pada Agroindustri Tepung Tapioka per Satu Kali Proses Produksi Tahun 2018

\begin{tabular}{|c|c|c|}
\hline No & Uraian & Jumlah \\
\hline 1 & Penerimaan (Rp) & 22.560 .000 \\
\hline 2 & Biaya Total (Rp) & 19.936 .494 \\
\hline 3 & Pendapatan (Rp) & 2.623 .506 \\
\hline 4 & $\mathrm{R} / \mathrm{C}$ & 1,13 \\
\hline
\end{tabular}

Sumber : Data primer diolah, 2019

Tabel 4 menunjukkan bahwa nilai $\mathrm{R} / \mathrm{C}$ pada pengusaha tepung tapioka adalah 1,13 . Artinya setiap mengeluarkan biaya Rp. 1.00.- akan menghasilkan penerimaan Rp. 1,13.- dan pendapatan Rp. 0,13. Sehingga nilai R/C lebih dari 1, maka dapat disimpulkan bahwa agroindustri tepung tapioka tersebut mengutungkan dan layak untuk diteruskan.

\section{KESIMPULAN DAN SARAN Kesimpulan}

Berdasarkan hasil penelitian dan pembahasan, maka dapat diambil kesimpulan sebagai berikut :

1. Biaya yang dikeluarkan oleh pengusaha agroindustri tepung tapioka dalam satu kali proses produksi adalah Rp 19.936.494 Penerimaan Rp 22.560.000. Sehingga memperoleh pendapatan $\mathrm{Rp} 2.623 .506$ dalam satu kali proses produksi, dengan jumlah bahan baku $10.000 \mathrm{~kg}$.
2. Besarnya $\mathrm{R} / \mathrm{C}$ agroindustri tepung tapioka adalah 1,13. Artinya setiap mengeluarkan biaya Rp. 1.00 akan menghasilkan penerimaan $\mathrm{Rp} 1,13$ dan pendapatan $\mathrm{Rp}$ 0,13. Nilai R/C lebih dari satu maka agroindustri tepung tapioka di perusahaan tersebut menguntungkan.

\section{Saran}

Berdasarkan hasil penelitian serta dilihat dari hasil pembahasan maka saran yang dapat disampaikan :

1. Dilihat dari besarnya pendapatan dan nilai $\mathrm{R} / \mathrm{C}$ pada agroindustri tepung tapioka dalam satu kali proses produksinya, maka agroindustri tepung tapioka ini diharapkan menjadi salah satu alternatif pilihan sebagai sumber pendapatan.

2. Agar perajin agroindustri tepung tapioka mempertahankan usahanya dan konsisten untuk terus mengembangkan usaha dengan meningkatkan produksi dan 
meningkatkan mutu produksi sehingga

pendapatan terus meningkat.

\section{DAFTAR PUSTAKA}

Arwati, S.2018. Pengantar Ilmu Pertanian Berkelanjutan. Inti Mediatama. Makassar.

Badan Ketahanan Pangan dan Penyuluhan. 2012. Kandungan Nutrisi pada Tepung Tapioka. Yogyakarta.

Baharsyah, S. 2009. Pengembangan Agribisnis dan Agroindustri di Indonesia. Departemen Pertanian. Jakarta.

Dinas Perindustrian dan Perdagangan. 2017. Data Agroindustri Tepung Tapioka di Kabupaten Tasikmalaya. Tasikmalaya.

Ismini. 2010. Analisis Nilai Tambah dan Strategi Pemasaran Keripik Singkong di Perusahaan "Mickey Mouse" di Malang. Agrika, Vol. 4 No. 2. Hal. 122

Kasmir. 2009. Pengantar Manajemen Keuangan. Kencana. Jakarta.

Mamandol, M. 2016. Analisis Kelayakan Ekonomi Usahatani Padi Sawah di Kecamatan Panoma Pusalemba. Jurnal Envira. Vol. 1 No. 2. Hal. 23

Maulidah, S. 2012. Pengantar Usahatani : Kelayakan Usahatani. Fakultas Pertanian Brawijaya University. Malang.

Nafarin. 2009. Pengantar Manajemen. Kencana. Jakarta.

Pratiwi, A. dkk. 2015. Peran Agroindustri Hulu dan Hilir dalam perekonomian dan Distribusi Pendapatan di Indonesia. E. Journal. Hal. 130

Rahman, S. 2018. Membangun Pertanian dan Pangan Untuk Mewujudkan Kedaulatan Pangan. CV. Budi Utama. Makassar.
Rahim, dan Hastuti. 2007. Ekonomika Pertanian. Penebar Swadaya. Jakarta.

Rodjak, A. 2006. Manajemen Usahatani. Pustaka Giratuna. Bandung.

Sari, R.P. 2011. Analisis Nilai Tambah dan Kelayakan Usaha Agroindustri Chip Ubi Kayu Sebagai Bahan Baku Pembuatan Mocaf (Modified Cassava Flour) di Kabupaten Trenggalek Malang. Vol. 1 No 2. Hal 6

Sihombing, M. 2014. Kinetika Hidrolisis Pembentukan Gula Pereduksi Dengan Pengaruh Variasi Konsentrasi HCL dan Temperatur Hidrolisis. Politeknik Negeri Sriwijaya. Palembang.

Sjamsir, Z. 2017. Pembangunan Pertanian dalam Pusaran Kearifan Lokal. CV. Sah Media. Makassar.

Sugiyono. 2018. Metode Penelitian Kuantitatif, Kualitatif, dan $R \& D$. $\mathrm{CV}$. Alfabeta. Bandung.

Soekartawi. 2006. Agribisnis Teori dan Aplikasi. Rajawali Press. Jakarta.

Soekartawi. 2010. Ilmu Usahatani dan Pengembangan Petani Kecil. Universitas Indonesia Press. Jakarta.

Suprapto, T. 2011. Pengantar Ilmu Komunikasi dan Peran Manajemen Dalam Pertanian. CV. Budi Utama. Makassar.

Suprapti, L. 2005. Tepung Tapioka Pembuatan dan Pemanfaatannya. Kanisius. Yogyakarta.

Suratiyah, K. 2015. Ilmu Usahatani. Penebar Swadaya. Jakarta.

Susilawati, dkk. 2018. Karakteristik Sifat Fisik dan Kimia Ubi Kayu (Manihot esculenta Berdasarkan Lokasi dan Umur Panen Berbeda. Jurnal Teknologi Industri dan Hasil Pertanian. Vol. 13 No 2. Hal 59.

Sutardi. 2007. Pelestarian Lingkungan Hidup. PT. Setia Purna. Bogor. 